\title{
Mobile Technology Integration in the 2020s: The Impact of Technology Leadership in the Malaysian Context
}

\author{
Mohd Norakmar Omar ${ }^{1,2, *}$, Siti Noor Ismail ${ }^{1}$ \\ ${ }^{1}$ School of Education and Modern Languages, Universiti Utara Malaysia, Malaysia \\ ${ }^{2}$ Scholarship and Finance Division, Ministry of Education (Malaysia), Malaysia
}

Received February 11, 2020; Revised March 20, 2020; Accepted March 28, 2020

Copyright $\bigcirc 2020$ by authors, all rights reserved. Authors agree that this article remains permanently open access under the terms of the Creative Commons Attribution License 4.0 International License

\begin{abstract}
Mobile technology is a growing technology in the education system around the world. Today's educational resources are easily accessible by using mobile technology at anytime and anywhere. As mobile technology is so essential, principals should play a vital role in stimulating teachers' efforts to use these devices as teaching aids in the classroom. Therefore, the purpose of this study is to identify the level of technology leadership, mobile technology integration and the relationship between the two variables. In addition, the study examines the influence of principals' technology leadership dimensions such as visionary leadership, digital age learning culture, excellence in professional practice, systemic improvement, and digital citizenship as predictors of teachers' mobile technology integration in teaching. A total of 376 secondary school teachers in the state of Kedah, Northern of Malaysia were selected as respondents through a quantitative approach involving systematic random sampling. This study also uses two instruments, namely the Principals Technology Leadership Assessment (PTLA) based on the NETS-A and UTAUT2. The results of the data analysis revealed that there is a strong positive relationship between principals' technology leadership and teachers' mobile technology integration in teaching process. Meanwhile, the findings also predicted that visionary leadership, systemic improvement and digital citizenship were the most significant contributors in influencing teachers to integrate mobile technology at secondary schools.
\end{abstract}

Keywords Technology Leadership, Mobile Technology, Technology Acceptance, Mobile Device, Pedagogy

\section{Introduction}

In today's educational world, the involvement of information and communication technology (ICT) is highly demanded to be consistent with current technological developments. Therefore, pedagogical approaches need to change from the traditional use of chalk and talk to the integration of the latest technology devices [1]. Technology has successfully transformed teachers into teaching strategies and facilitated the day-to-day routine of implementing the existing curriculum [2]. This makes the quality of teachers more effective in providing the best service for the students. Learning approaches such as augmented reality, virtual reality and even mobile learning that have interactive elements bring students an excitement to learn more.

In Malaysia, Ministry of Education Malaysia (MOE) has made various efforts to generate higher quality education in line with the 21 st-century learning concept. MOE has been establishing collaboration several companies in realizing the potential of education towards digitizing knowledge [3]. For the record, the MOE has launched the 1 BestariNet project involving over 10,000 schools across the country through the provision of ICT infrastructure and high-speed Internet access [4]. Thus, the seventh shift of the Malaysian Education Development Plan (PPPM 2013-2025) in the first wave can be achieved by "utilizing ICT to enhance the quality of learning in Malaysia" [5].

Today, various online education platforms such as Google Classroom, Kahoot, Plickers, and Tarsia help teachers and students to explore knowledge more efficiently. For example, Google Classroom is capable of increasing resource access, facilitating collaboration and sharing information quickly [6]. Besides, the presence of mobile technology devices such as smartphones, tablets, and laptops has introduced a completely new dimension for the school community to achieve something. This is through mobile applications. Basically, mobile technology devices allow resources to be accessed at their fingertips. In addition, their devices are small, lightweight and easy 
to carry anywhere, which provide a huge advantage for them [7]. Hence, mobile technology is no longer a requirement, but it is an obligation that every teacher and student should have [8].

\subsection{Problem Statements}

The development of mobile technology is faster than ever. It is rapidly spreading to all communities. From positive point of view, the use of the devices creates a fascinating phenomenon. Therefore, it is crucial to develop a mechanism to make sure that the advantages of mobile technology create a significant impact on the learning process [8]. In the past, most parents and students have agreed and expressed strong support for teachers to integrate mobile technology in the classroom [9]. Unfortunately, some teachers worry that mobile technology is being abused and instead of carrying the burden of their own tasks [10][11]. This situation also poses a significant disadvantage if teachers are still hesitant to accept the benefits of mobile technology as one of the latest teaching mediums [12].

Meanwhile, the abundant of educational resources and current teaching methods is increasing in the educational world. The use of educational software, system database applications and organizational management through mobile technology makes it easier to access [13]. Like it or not, several strategies need to be implemented to make mobile technology more effective in learning. Thus, the role of principals is vital in defining clearly the goals of integrating mobile technology through ICT strategic planning [14]. However, not all principals can effectively lead and execute the ICT strategic planning process [15][16]. Moreover, some principals are unconfident and lack of competency to handle the matters related to ICT integration in schools [17].

By examining this situation, a study needs to be conducted to identify the influence of principals' technology leadership on teachers' mobile technology integration based on the model of National Educational Technology Standards for Administrations (NETS-A). Previously, the NETS-A has proven its impact on $21 \mathrm{st}$ Century technology integration [18], educational administrator readiness [17], teacher ICT competence [19] as well as professional development [20]. Therefore, the NETS-A should be introduced to examine its impact on the use of the latest ICT devices that enhance the quality of teaching and learning [15].

\subsection{Research Objectives}

The objectives of this study are as follows:

1) To determine the level of principals' technology leadership and mobile technology integration,
2) To determine the differences in teachers' mobile technology integration based on demographic factors (gender and age),

3) To identify the relationship between principals' technology leadership and mobile technology integration,

4) To identify the effect of principals' technology leadership on mobile technology integration.

\section{Literature Review}

\subsection{Technology Leadership}

Technology leadership is a style of leadership that focuses on leaders' characters in uplifting the spirit of the workforce into applying the technology within the organization [21]. Leaders who practice technology leadership should have high ICT competencies [19], smartly develop ICT potential in organizations [22], and influence employees to use ICT more effectively [23]. In schools, principals play an essential role in creating a technology-based learning environment while leading organizations towards digitizing education. Through ICT, school management systems can be managed more efficiently than any other organization today. The teaching and learning process is also planned through an ICT strategic plan to align with the digital age learning culture [24].

The history of technology leadership flourished in the educational around the early 2000s. At that time, the studies of [25] and [26] have presented a model that guides the existence of technological leadership in the education system. According to [25], that concern is how to find the best way to integrate the emerging technologies with existing curriculum. In simple terms, at that time, there were no well-established guidelines to articulate the role of school leaders in coordinating and managing ICT in planning [26]. To ensure that ICT is implemented effectively, five elements need to be emphasized namely student engagement, vision sharing, access equity, networking everywhere and professional development programs [25].

In 2009, the International Society for Technology in Education (ISTE) launched the latest NETS-A model with improvements to the previous NETS-A. At the same time, the ambiguity of existing technological leadership models [25][26] has also been interpreted in building this model. These gaps are consolidated to form the roles of educational leaders with ICT as the main focus of curriculum implementation [27]. Finally, a new NETS-A model was released, as illustrated in Figure 1 below. 


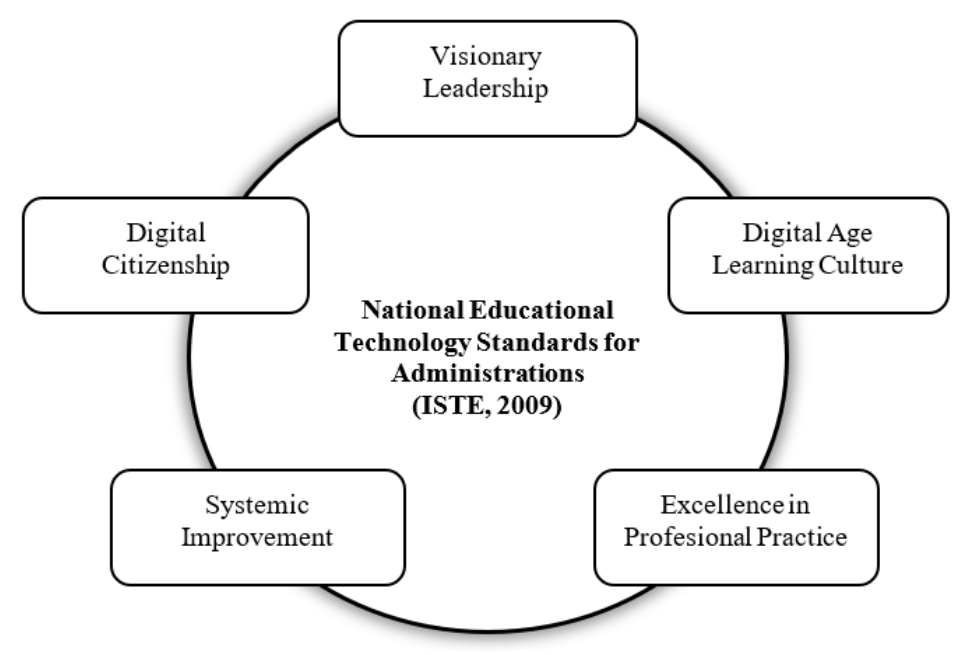

Figure 1. Five Elements of NETS-A Model

Studies involving NETS-A have been carried out in several countries. For example, [17] found that most principals in the United States still lacked the NETS-A standards as a whole. In Turkey, only $55 \%$ of principals agree with the criteria proposed by the NETS-A. Although, it was proven in developing quality educational leaders in various institutions [28]. However, some studies demonstrate that NETS-A should be an essential guide for technology's leaders in the educational era. Research conducted in China shows that NETS-A has become a key channel for developing high-quality technology leaders through enhanced ICT competencies [20]. Meanwhile, the principals who practice NETS-A can uphold their authority in influencing teachers to integrate ICT at a high level [19][29].

\subsection{Mobile Technology Integration}

The integration of mobile technology refers to the use of mobile devices such as smartphones, tablets, laptops and notebooks to perform tasks, entertain and communicate. These devices have features that are portable, accessible anywhere, capable of interacting and sharing resources [30]. Recently, mobile technology increasingly being used to improve the quality of pedagogy [31]. Specifically, a study by [12] found that applications in mobile technology have made it easier for teachers to translate more complex Math content. There is also the use of immersive technologies such as augmented and virtual reality in increasing the teaching effectiveness such as some Geography topics that are difficult to describe in traditional ways [32].

Previously, there have been several studies that have examined consumer acceptance of technology integration such as internet usage, e-banking and mobile learning [33][34][35]. The study of [35], proposes seven elements that drive consumer acceptance of technology, namely performance expectancy, effort expectancy, social influence, facilitating conditions, hedonic motivation, price value and habit. These elements have been widely adapted to most international studies in various fields. Among them, [36] it is found that social influence, such as technical supports and infrastructures, should be provided sufficiently to stimulate the passion of teachers in integrating mobile technology in the classroom. At the same time, inexpensive, capable and affordable devices are among the most significant contributors to consumer confidence in incorporating mobile technology into a daily routine [34].

Through the literature, the question of teacher readiness and acceptance of mobile technology in teaching has emerged. Although mobile technology has been proven effective in improving learning outcomes, some teachers find it challenging to apply these advantages in the classroom [10][36]. According to the study of [10], teachers are very concerned about integrating mobile technology because they are worried that the workload will increase. Worse, there are also groups of school leaders who do not encourage teachers to use these devices due to the disruption of the learning process and students' focus [11][37]. In fact, only $31.9 \%$ of teachers use mobile technology for teaching purposes, while the rest are for personal purposes [11]. Therefore, a new approach needs to be taken to ensure that mobile technology is not abused and provides the best learning outcomes for the entire school community.

\subsection{Research Framework}

In this study, the principals' technology leadership has five dimensions, namely visionary leadership, digital age learning culture, excellence in professional practice, systemic improvement and digital citizenship. These five dimensions refer to the NETS-A model introduced by [38]. Each aspect is tested to determine whether it has an impact on teachers' mobile technology integration in teaching. Figure 2 below shows the research framework in this study. 


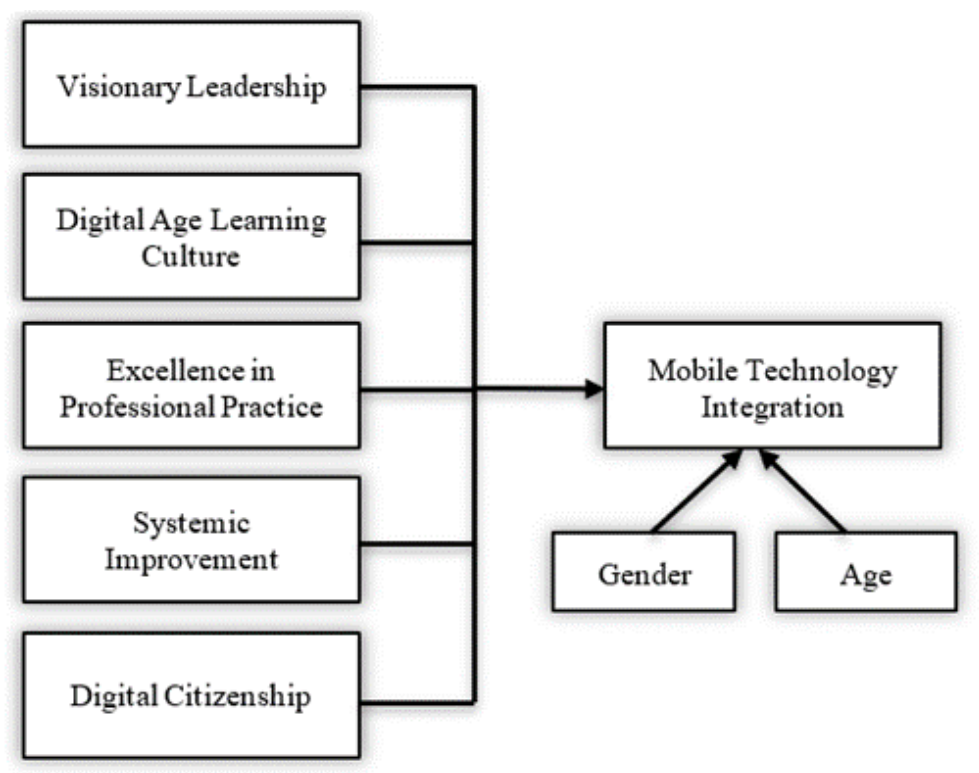

Figure 2. Research Framework

\section{Methodology}

This study is a cross-sectional study of the principals' technology leadership and mobile technology integration of secondary school teachers in Kedah, North of Malaysia. Therefore, quantitative approaches are used to collect survey data based on large populations. According to [39], quantitative methods are used to help researchers obtain data more quickly, process information faster, and save on research costs. This situation coincides with the use of a large number of respondents as well as extensive study locations.

\subsection{Population and Sampling}

The target population is secondary school teachers around Kedah. According to [40], the community should be selected based on a group of similar elements based on the purpose of the study. The homogeneous aspects of the population must be emphasized for the objectives of the study to be achieved. Based on the current society, the number of teachers in secondary schools in the study area is 14186 . Thus, 376 teachers were selected as respondents, involving 24 secondary schools. The location of the school is chosen evenly in the urban and rural areas.

Systematic random sampling method was used to select the teacher sample. However, it needs to follow several criteria to ensure that the sample selection is accurate. Some of these criteria are subject to the following:

1) the teachers served at least six months in the school,

2) the teachers are a qualified trained teachers,

3) the teachers have at least one mobile technology device used for educational purposes.

\subsection{Instrumentation}

The technology leadership instrument was adapted from the Principle Technology Leadership Assessment (PTLA) presented by [38] and is in line with the study of [19]. According to [38], 21 criteria describe the character of technology leaders in education, while [19] expanded this criterion to 32 items based on her study of teachers in Negeri Sembilan, Malaysia. As a result, the two instruments were combined and adapted to 32 items following the current study situation and location. Meanwhile, mobile technology integration instruments were adapted from the original Unified Theory of Acceptance and Use of Technology (UTAUT2) developed by [35]. Overall, 35 items were used to identify the variables of teachers' mobile technology integration in teaching.

Meanwhile, a pilot study session was conducted to test the reliability of the instrument. According to [40], a pilot study was used to test its effectiveness, logic and reasonableness before it was distributed to real respondents. Through a pilot study, Cronbach's Alpha $(\alpha)$ values were observed in determining reliability values. This degree of reliability ensures that each item submitted has a high degree of consistency and thus qualifies for use in the actual study [41]. Hence, the reliability of the instrument is shown in Table 1 below.

Table 1. Reliability of Instruments

\begin{tabular}{|l|l|c|c|}
\hline Code & Sections & Items & $\boldsymbol{\alpha}$ \\
\hline VL & Visionary Leadership & 5 & 0.94 \\
LC & Digital Age Learning Culture & 6 & 0.92 \\
PP & Excellence in Professional Practice & 7 & 0.92 \\
SIM & Systemic Improvement & 6 & 0.92 \\
DC & Digital Citizenship & 8 & 0.91 \\
\hline & Overall: & & \\
& Technology Leadership & 32 & 0.91 \\
& Mobile Technology Integration & 35 & 0.93 \\
\hline
\end{tabular}




\subsection{Data Analysis}

The data analyses involved are descriptive analysis and inference analysis. Descriptive statistics describes respondents' backgrounds such as gender, age and school location using mean and standard deviation [40]. The mean value is used to determine the level of study variables. Meanwhile, inference analysis was generated to examine the relationship between principals' technology leadership and teachers' mobile technology integration through Pearson's correlation test. Lastly, multiple regression analysis was used to determine the predictive factors of principals' technology leadership dimensions towards teachers' mobile technology integration. These data were analyzed using Statistical Package for the Social Sciences (SPSS) version 24.0 with a significance level of $\mathrm{p}<0.05$.

\section{Findings}

\subsection{Profile of the Respondents}

The respondents in this study were 376 teachers, which 104 teachers were male $(27.7 \%)$, and 272 teachers were female $(72.3 \%)$. The age group of teachers between the ages of $41-50$ was the largest respondent group of 154 $(41.0 \%)$, followed by 123 teachers between the ages of 31 - 40 (32.7\%). Meanwhile, 83 teachers were over 50 years old $(22.1 \%)$, while only 16 teachers under 30 years old $(4.3 \%)$ were selected as respondents of the study. Data analysis also found that 196 teachers teach in urban areas (52.1\%), while the remaining 180 teachers $(47.9 \%)$ work in rural areas in the state of Kedah. The summary of the respondents' demographic analysis is shown in Table 2 below.

Table 2. Respondents by Gender, Age and School Location

\begin{tabular}{|l|l|c|c|}
\hline \multirow{2}{*}{ Gender } & Demographics & Frequencies & $\mathbf{\%}$ \\
\hline \multirow{4}{*}{ Age } & Men & 104 & $27.7 \%$ \\
& Women & 272 & $72.3 \%$ \\
\hline \multirow{2}{*}{ School Location } & Below 31 years old & 16 & $4.3 \%$ \\
& $31-40$ years old & 123 & $32.7 \%$ \\
& 41-50 years old & 154 & $41.0 \%$ \\
& Over 50 years old & 83 & $22.1 \%$ \\
\hline
\end{tabular}

\subsection{The Level of Principals' Technology Leadership and Teachers' Mobile Technology Integration}

The interpretation of data for the mean values in this study is categorized into five sections: very high (4.21 5.00), high (3.41 - 4.20), medium (2.61 - 3.40), low (1.81 - 2.60) and very low $(0.00-1.80)$ [42]. The categories are suitable, given that this study uses a 5-point scale for each item in the instrument. Based on the findings, it is found that the five dimensions of principals' technology leadership are high. The visionary leadership dimension showed the highest mean values compared to the other five dimensions $(\mathrm{M}=3.96, \mathrm{SD}=0.53)$, followed by digital age learning culture $(\mathrm{M}=3.86, \mathrm{SD}=0.57)$, excellence in professional practice $(\mathrm{M}=3.81, \mathrm{SD}=0.55)$ and digital citizenship $(\mathrm{M}=3.72, \mathrm{SD}=0.56)$. Dimensions of systemic improvement show the lowest mean value results compared to all five dimensions $(\mathrm{M}=3.70, \mathrm{SD}=$ 0.59). Overall, the level of technology leadership among principals in the state of Kedah showed a high level $(\mathrm{M}=$ $3.80, \mathrm{SD}=0.49$ ), as shown in Table 3 below.

Table 3. The Level of Principals' Technology Leadership

\begin{tabular}{|l|c|c|c|}
\hline Dimensions & M & SD & Level \\
\hline Visionary Leadership & 3.96 & 0.53 & High \\
Digital Age Learning Culture & 3.86 & 0.57 & High \\
Excellence in Professional Practice & 3.81 & 0.55 & High \\
Systemic Improvement & 3.70 & 0.59 & High \\
Digital Citizenship & 3.72 & 0.56 & High \\
\hline Overall & $\mathbf{3 . 8 0}$ & $\mathbf{0 . 4 9}$ & High \\
\hline
\end{tabular}

Furthermore, Table 4 shows the results of the seven dimensions of teachers' mobile technology integration where each dimension is at a high level. Performance expectancy $(\mathrm{M}=3.94, \mathrm{SD}=0.55)$ and hedonic motivation $(\mathrm{M}=3.94, \mathrm{SD}=0.58)$ recorded the highest mean values among the seven dimensions, followed by effort expectancy $(\mathrm{M}=3.72, \mathrm{SD}=0.58)$, habit $(\mathrm{M}=3.72, \mathrm{SD}=$ $0.57)$, facilitating conditions $(\mathrm{M}=3.64, \mathrm{SD}=0.58)$ and also price value $(\mathrm{M}=3.47, \mathrm{SD}=0.65)$. Meanwhile, social influence $(\mathrm{M}=3.43, \mathrm{SD}=0.59)$ showed the lowest mean values among the seven dimensions studied. Overall, the mean value of mobile technology integration variable among secondary school teachers in the state of Kedah showed a high level $(\mathrm{M}=3.69, \mathrm{SD}=0.47)$.

Table 4. The Level of Teachers' Mobile Technology Integration

\begin{tabular}{|l|c|c|c|}
\hline Dimensions & M & SD & Level \\
\hline Performance Expectancy & 3.94 & 0.55 & High \\
Effort Expectancy & 3.72 & 0.58 & High \\
Social Influence & 3.43 & 0.59 & High \\
Facilitating Conditions & 3.64 & 0.58 & High \\
Hedonic Motivation & 3.94 & 0.58 & High \\
Price Value & 3.47 & 0.65 & High \\
Habit & 3.72 & 0.57 & High \\
\hline Overall & $\mathbf{3 . 6 9}$ & $\mathbf{0 . 4 7}$ & High \\
\hline
\end{tabular}

\subsection{Differences in Teachers' Mobile Technology Integration Based on Gender and Age}

Based on the t-test, there was a significant difference between teacher gender and mobile technology integration, where $\mathrm{t}(374)=1.82, \mathrm{p}<0.01$. This situation illustrates that there is a difference between the level of mobile technology integration between male and female teachers in secondary schools in the state of Kedah. Male teachers outperformed the mean values of mobile technology integration $(\mathrm{M}=3.76, \mathrm{SD}=0.50)$ compared to female teachers $(\mathrm{M}=3.67, \mathrm{SD}=0.45)$. The results of the Levene's Test for Equality of Variance found that the 
$\mathrm{p}$-value was insignificant $(\mathrm{F}=0.43, \mathrm{p}>0.05)$, and this indicates that both genders have homogeneous and compliant variance. For further explanation, t-test analysis is illustrated in Table 5 below.

Table 5. A T-Test Analysis of Mobile Technology Integration by Gender

\begin{tabular}{|c|c|c|c|c|c|}
\hline Gender & N & M & SD & t-value & df \\
\hline Male & 104 & 3.76 & 0.50 & $1.82^{* *}$ & \multirow{2}{*}{374} \\
Female & 272 & 3.67 & 0.45 & & \\
\hline
\end{tabular}

Meanwhile, the ANOVA test found that no significant difference is in age of teacher for mobile technology integration, $\mathrm{F}(3,372)=1.19, \mathrm{p}<0.05$. In other words, there is no significant difference between the age and mobile technology integration of secondary school teachers in Kedah. However, Levene's Test for Equality of Variance showed insignificant values $(\mathrm{F}=1.81$, sig. $=$ $0.145)$, suggesting that the variance for age groups was homogeneous and observed. According to Table 6, a group of teachers over 50 years old showed the highest mean level of mobile technology integration $(\mathrm{M}=3.77$, $\mathrm{SD}=0.53)$, followed by a group of teachers under 31 years old $(\mathrm{M}=3.69, \mathrm{SD}=0.45)$, and the teachers were 41 - 50 years old $(\mathrm{M}=3.68, \mathrm{SD}=0.44)$. Meanwhile, the group of teachers between 31 - 40 years old had the lowest mean values $(\mathrm{M}=3.64, \mathrm{SD}=0.45)$ in using mobile technology as teaching aids in the classroom.

Table 6. An ANOVA Analysis of Mobile Technology Integration by Age

\begin{tabular}{|l|c|c|c|c|c|}
\hline Age (years old) & N & M & SD & F & df \\
\hline Below 31 & 16 & 3.69 & 0.45 & 1.19 & 3,372 \\
$31-40$ & 123 & 3.64 & 0.45 & & \\
$41-50$ & 154 & 3.68 & 0.44 & & \\
Over 50 & 83 & 3.77 & 0.53 & & \\
\hline
\end{tabular}

\subsection{Relationship between Principals' Technology Leadership and Teachers' Mobile Technology Integration}

Table 7 below shows the relationships between principals' technology leadership and teachers' mobile technology integration. Based on the Pearson's correlation coefficient (r), both variables are strongly correlated [39], with $\mathrm{r}=0.686, \mathrm{p}=0.00(\mathrm{p}<0.01)$. This situation demonstrates that principals who practice technology leadership have a strong connection to the integration of mobile technology among teachers in secondary schools around Kedah. The results of the Pearson's correlation are shown in Table 7 below.

Table 7. Correlation Analysis between Principals' Technology Leadership and Teachers' Mobile Technology Integration

\begin{tabular}{|c|c|c|c|}
\hline Variables & & TL & MT \\
\hline TL & Pearson's Correlation & 1 & $\mathbf{0 . 6 8 6}^{* *}$ \\
& Sig. (2-tailed) & & 0.00 \\
MT & Pearson's Correlation & $\mathbf{0 . 6 8 6 * *}$ & 1 \\
& Sig. (2-tailed) & 0.00 & \\
\hline
\end{tabular}

(Note: TL - Technology Leadership; MT - Mobile Technology Integration)
Five dimensions of principals' technology leadership are tested in the search for correlation with teachers' mobile technology integration. Systemic improvement and digital citizenship showed a significant and strong correlation between the five dimensions $(r=0.628, \mathrm{p}$ $<0.01$ ), followed by excellence in professional practice ( $\mathrm{r}$ $=0.614, \mathrm{p}<0.01)$ and digital age learning culture $(\mathrm{r}=$ $0.587, \mathrm{p}<0.01)$. On the other hand, the dimension of visionary leadership had the lowest correlation among the five dimensions $(\mathrm{r}=0.534, \mathrm{p}<0.01)$. The results of these correlations are summarized as Table 8 below.

Table 8. Correlation Analysis Based on Principals' Technology Leadership Dimensions

\begin{tabular}{|l|l|c|}
\hline & Dimensions & MT \\
\hline & Visionary Leadership & $\mathbf{0 . 5 3 4 * *}$ \\
& Sig. (2-tailed) & 0.00 \\
& N & 376 \\
& Digital Age Learning Culture & $\mathbf{0 . 5 8 7 * *}$ \\
& Sig. (2-tailed) & 0.00 \\
& N & 376 \\
Pearson's & Excellence in Professional Practice & $\mathbf{0 . 6 1 4 * *}$ \\
Correlation & Sig. (2-tailed) & 0.00 \\
& N & 376 \\
& Systemic Improvement & $\mathbf{0 . 6 2 8 * *}$ \\
& Sig. (2-tailed) & 0.00 \\
& N & 376 \\
& Digital Citizenship & $\mathbf{0 . 6 2 8 * *}$ \\
& Sig. (2-tailed) & 0.00 \\
& N & 376 \\
\hline
\end{tabular}

(Note: MT - Mobile Technology Integration)

\subsection{The Effect of Principals' Technology Leadership on Teachers' Mobile Technology Integration}

Based on the multiple linear regression analysis, the results are presented, as shown in Table 9 below. The value of $\mathrm{R}^{2}$ describes the amount of the variance for the teachers' mobile technology integration as a dependent variable. This means that the five dimensions of principals' technology leadership contribute $47.40 \%$ to teachers' mobile technology integration in secondary schools around Kedah. $\mathrm{R}^{2}$ needs to be reported when respondent size is more than 100 . Meanwhile, the value of $\mathrm{F}=66.628$ in the ANOVA analysis indicated that there was a significant difference between principals' technology leadership and teachers' mobile technology integration ( $\mathrm{sig} .=0.00 \mathrm{p}<0.05)$.

Table 9. Multiple Linear Regression Analysis between Principals' Technology Leadership on Teachers' Mobile Technology Integration

\begin{tabular}{|l|c|c|c|}
\hline Dimensions & Beta & T & Sig \\
\hline (constant) & & 8.773 & 0.000 \\
Visionary Leadership & 0.119 & 2.126 & $\mathbf{0 . 0 3 4}$ \\
Digital Age Learning Culture & 0.092 & 1.331 & 0.184 \\
Excellence in Professional Practice & 0.119 & 1.636 & 0.103 \\
Systemic Improvement & 0.212 & 3.141 & $\mathbf{0 . 0 0 2}$ \\
Digital Citizenship & 0.239 & 3.499 & $\mathbf{0 . 0 0 1}$ \\
\hline R $^{2}$ value & & & 0.474 \\
Adjusted R ${ }^{2}$ value & & & 0.467 \\
F Value & & & 66.628 \\
Sig. & & & $\mathbf{0 . 0 0 * *}$ \\
\hline
\end{tabular}


Based on Table 9, the findings show that the three dimensions of principals' technology leadership are contributing significantly to teachers' mobile technology integration. The digital citizenship dimension $(\beta=0.239$, $p<0.05)$ accounted for the largest significant effect followed by systemic improvement $(\beta=0.212, p<0.05)$ and visionary leadership $(\beta=0.119, \mathrm{p}<0.05)$. However, two other dimensions of excellence in professional practice $(\beta=0.119, \mathrm{p}>0.05)$ and digital age learning culture $(\beta=0.092, p>0.05)$ contributed to the significant impact of mobile technology integration among secondary school teachers in Kedah. Overall, the principals' technology leadership dimension contributed $47.4 \%$ of which $\mathrm{R}^{2}$ value was 0.474 .

\section{Discussions}

The existence of NETS-A is indeed anticipated by most technology leaders around the world. The success of ISTE in establishing the characteristics of technology leadership deserves the highest recognition of any educational organization that practices it. Notably, in most studies, the NETS-A has shown that there are positive signs in building the character of prominent educational leaders [18][19][20]. Although there are differences in items in the PTLA, in most studies, they still use the original NETS-A instrument as their primary reference. For example, the study of [18] proves that all dimensions of PTLA are high. This is supported by [19], who acknowledged that technology leadership levels would be high if all principals are able to increase ICT competencies. Therefore, these studies support this finding where the level of principals' technology leadership in Kedah is high.

As expected, the findings show that the level of mobile technology integration is also high. This situation is in fact supported by previous studies where mobile technology can stimulate teachers' action in improving the quality of teaching and produce a more entertaining learning process [43][44]. The study by [2] found that the level of teachers' mobile technology integration would be higher if the authorities are able to overcome issues such as providing infrastructure facilities and high-speed internet access. The results of the analysis are also supported by [45] where the level of teachers' concerns in the use of mobile technology can be overcome if training and self-efficacy in ICT are adequately addressed. Ongoing training will increase teachers' confidence to adapt to the current variety of educational applications.

Regarding gender, the findings show that there are significant differences between male and female teachers in the use of mobile technology. Male teachers are more likely to integrate these devices as teaching aids in the classroom more than female teachers. This statement is also supported by [46], where male teachers are increasingly prepared to use the latest technology and online learning resources. Male teachers are often more accessible and receptive to every innovation in education than female teachers, especially in the use of technology [47]. Previously, studies using the UTAUT have also shown that male teachers are more significant in integrating mobile technology despite the unsatisfactory internet access problems and lack of technology-based pedagogical approaches [36].

From a traditional perspective, age factors also determine the frequency of ICT used in the daily routine. However, the findings suggest that the age of teachers did not show significant differences in mobile technology integration, especially in teaching. Previously, [48] found that age is not a barrier for teachers to accept the presence of new technologies such as online learning. The findings of [49] summarize that all teachers use technology devices for more than six hours a week for teaching purposes when they have high self-efficacy. In other words, age is not a significant issue for the teachers to use mobile technology such as smartphones or tablets, but it is essential to implement mobile learning concept.

Further, the study also found a strong correlation between the principals' technology leadership and the teachers' mobile technology integration. As we know, principals are individuals who can lead and influence teachers to perform a task based on their intended goals [50]. This case involves implementing pedagogical processes based on the latest technology devices. According to a study by [51], technology leaders are crucial to enhance the integration of the latest technologies while providing all ICT infrastructure for the school community. Principals are also responsible for providing training opportunities and professional development programs for teachers to enhance ICT competencies in the latest applications [19][20].

The final objective of this study was to determine the dimensions of principals' technology leadership that influence teachers' mobile technology integration. In this matter, the aspects of digital citizenship, systemic improvement and visionary leadership accounted for $47.4 \%$ of the impact of teachers' mobile technology integration among secondary schools in Kedah. Previous studies such as [27] have found that digital citizenship is also a significant contributor to technology integration. Principals who practice digital citizenship will try to encourage teachers to integrate technology for effective teaching. Digital citizenship also creates flexible principals by allowing the school community to explore the diversity of online knowledge and open-source whenever needed [23].

Meanwhile, principals who practice systemic improvement have strong potential in developing schools towards the holistic implementation of ICT. Despite the challenges, principals can lead the school community as well as to create the possibility of implementing new 
technologies gradually and ultimately, throughout the organization [52]. In the study of [19], principals who practice systemic improvement have a significant impact on teachers' ICT competencies in using technology tools and resources. Another dimension of visionary leadership also had a significant effect on teacher's technology integration in the classroom [22]. This was even touched upon by [51], who agreed that visionary leadership could provide a shared vision in encouraging teachers to create high impact pedagogical methods through technology tools.

\section{Conclusions}

Today's mobile technology integration is gaining popularity among teachers and students. Teachers have an excellent opportunity to develop pedagogical methods through mobile technology that are considered as teaching aids in the classroom. At the same time, mobile technology can create a more exciting and interactive learning environment. This phenomenon will increase students' involvement in all activities undertaken by teachers [53]. Through the latest educational applications, teachers can explore and generate more ideas for a better learning experience [30]. This also helps to bridge the educational gap between urban and rural students that are previously covered by issues such as lack of ICT resources and infrastructure [51].

Taking everything into account, principals play a crucial role in ensuring that technology is integrated into their organizations. As a leader, they can leverage the talent and potential of teachers to produce superior pedagogical methods. Thus, 21st-century learning, as mentioned earlier, can be realized through more extreme approaches such as augmented reality, virtual reality or mobile learning. It is hoped that future studies will explore more of the effects of technology leaders on more specific teacher pedagogical approaches.

\section{Acknowledgments}

This article was conducted as part of a doctoral study by the first author at Universiti Utara Malaysia. This author is fully sponsored by the Ministry of Education Malaysia (MOE), under the Federal Training Gift Program (HLP) for recruitment in 2018.

\section{REFERENCES}

[1] J. E. Lawrence, and U. A. Tar, "Factors that influence teachers' adoption and integration of ICT in teaching/learning process", Educational Media International, vol. 55(1), 2018, pp. 79-105.
[2] Z. Khlaif, F. Gok, and B. Kouraichi, "How teachers in middle schools design technology integration activities", Teaching and Teacher Education, vol. 78, 2019, pp. 141-150.

[3] J. Gryzelius, "ICT in classroom learning: Exploring the discrepancies between ideal conditions and current Malaysian policy, Policy Ideas, vol. 18(1), 2015, pp. 1-14.

[4] M. Mai, and R. M. Ghaneshwary, "Primary school science teachers' attitude towards using Virtual Learning Environment (VLE) in teaching science", European Journal of Education, vol. 1(3), 2018, pp. 155-162.

[5] MOE, Pelan Pembangunan Pendidikan Malaysia 2013 2015, Putrajaya: KPM, 2013.

[6] K. R. Heggart, and J. Yoo, "Getting the most from google classroom: A pedagogical framework for tertiary educators", Australian Journal of Teacher Education, vol. 43(3), 2018, pp. 140-153.

[7] B. Hegarty, and M. Thompson, "A teacher's influence on student engagement: Using smartphones for creating vocational assessment eportfolios", Journal of Information Technology Education: Research, vol. 18, 2019, pp. 113-139.

[8] J. Osakwe, N. Dlodlo, and N. Jere, “Learners' perceptions on the adoption of mobile technology in high schools: A case of Otjozondjupa region in Namibia", in P. Cunnigham \& M. Cunnigham (Eds.), IST-Africa 2017 Conference Proceedings , 2017, pp. 1-7, IEEE.

[9] G. Mwandosya, C. S. Montero, and E. R. Mbise, "Information Systems and Technologies to Support Learning", in A. Rocha \& M. Serrhini (Eds.), Information Systems and Technologies to Support Learning, vol. 111, 2017, pp. 56-66, Cham: Springer International Publishing.

[10] T. K. F. Chiu, and D. Churchill, "Adoption of mobile devices in teaching: Changes in teacher beliefs, attitudes and anxiety", Interactive Learning Environments, vol. 24(2), 2015, pp. 317-327.

[11] Z. Abidin, A. Mathrani, R. Hunter, and D. Parsons, "Challenges of integrating mobile technology into Mathematics instruction in secondary schools: an Indonesian context", Computers in the Schools, vol. 34(3), 2017, pp. 207-222.

[12] R. Tahir, and F. Arif, "Technology in primary schools: teachers' perspective towards the use of mobile technology in children education", in L. Chen, S. Kapoor, \& R. Bhatia (Eds.), Emerging Trends and Advanced Technologies for Computational Intelligence, vol. 647, 2016, pp. 103-129, Cham: Springer International Publishing.

[13] C. Dong, and L. Newman, "Enacting pedagogy in ICT-enabled classrooms: Conversations with teachers in Shanghai", Technology, Pedagogy and Education, vol. 27(4), 2018, pp. 499-511.

[14] M. N. Omar, S. N. Ismail, and A. L. Kasim, "Hubungan kepimpinan teknologi pengetua dan efikasi kendiri guru", Jurnal Kepimpinan Pendidikan, vol. 6(4), 2019, pp. 1-21.

[15] M. I. M. Hamzah, F. Juraime, and A. N. Mansor, "Malaysian principals' technology leadership practices and curriculum management", Creative Education, vol. 7, 2016, pp. 
$922-930$.

[16] N. L. Okeke, and H. I. Dike, "Head teachers' technology leadership competencies and ICT integration in model primary schools in Rivers State", International Journal of Innovative Information Systems \& Technology Research, vol. 7(1), 2019, pp. 14-21.

[17] N. L. Esplin, C. Stewart, and T. N. Thurston, "Technology leadership perceptions of Utah elementary school principal", Journal of Research on Technology in Education, vol. O(0), 2018, pp. 1-14.

[18] A. Raman, R. Thannimalai, and S.N. Ismail, "Principals' technology leadership and its effect on teachers' technology integration in 21 st century classrooms", International Journal of Instruction, vol. 12(4), 2019 pp. 423-442.

[19] L. M. Wei, C. Y. Piaw, and S. Kannan, "Relationship between principal technology leadership practices and teacher ICT competency", Malaysian Online Journal of Educational Technology, vol. 4(3), 2016, pp. 13-36.

[20] C. Yu, and D. L. Prince, “Aspiring school administrators' perceived ability to meet technology standards and technological needs for professional development", Journal of Research on Technology in Education, vol. 48(4), 2016, pp. 239-257.

[21] A. P. Srivastava, and Y. Joshi, "Examining the role of technology leadership on knowledge sharing behaviour", International Journal of Knowledge Management, 14(4), 2018, pp. 13-29.

[22] N. G. Ugur, and T. Koc, "Leading and teaching with technology: School principals' perspective", International Journal of Educational Leadership and Management, vol. 7(1), 2019, pp. 42-71.

[23] U. Akcil, Z. Altinay, D. Dagli, and F. Altinay, "The role of technology leadership: Innovation for school leadership in digital age", in The 15th International Scientific Conference eLearning and Software for Education, 2019 pp. 323-329.

[24] A. Garcia, and J. Abrego, "Elementary principal's technology leadership dispositions", Global Journal of Human-Social Science, vol. 14(9), 2014, pp. 1-12.

[25] L. Flanagan, and M. Jacobsen, “Technology leadership for the twenty-first century principal", Journal of Educational Administration, vol. 41(2), 2003, pp. 124-142.

[26] R. E. Anderson, and S. Dexter, "School technology leadership: An empirical investigation of prevalence and effect”, Educational Administration Quarterly, vol. 41(1), 2005, pp. 49-82.

[27] W. Metcalf, and J. LaFrance, "Technology leadership preparedness: Principals' perceptions", Journal of Research in Education, vol. 23(1), 2013, pp. 58-75.

[28] K. Banoglu, R. Vanderlinde, and M. Cetin, "Investigation of principals' technology leadership profiles in the context of schools' Learning organization culture and ICT infrastructure: F@tih project schools vs the others", Education and Science, vol. 41(188), 2016, pp. 83-98.

[29] R. Thannimalai, and A. Raman, "Principals' technology leadership and teachers' technology integration in the $21 \mathrm{st}$ century classroom", International Journal of Civil Engineering and Technology, vol. 9(2), 2018, pp. 177-187.
[30] J. Leem, and E. Sung, “Teachers' beliefs and technology acceptance concerning smart mobile devices for SMART education in South Korea" British Journal of Educational Technology, vol. O(0), 2018, pp. 601-613.

[31] X. Zhai, M. Zhang, M. Li, and X. Zhang, "Understanding the relationship between levels of mobile technology use in high school physics classrooms and the learning outcome", British Journal of Educational Technology, vol. 50(2), 2018, pp. 750-766.

[32] I. Stojsic, A. Ivkov-Dzigurski, and O. Maricic, "The readiness of geography teachers to use mobile devices in the context of immersive technologies integration into the teaching process", Geographica Pannonica, vol. 23(2), 2019, pp. 122-134.

[33] V. J. Bharati, and R. Srikanth, "Modified UTAUT2 model for m-learning among students in India", International Journal of Learning and Change, vol. 10(1), 2018, pp. $5-20$.

[34] N. Shaw, and K. Sergueeva, "The non-monetary benefits of mobile commerce: Extending UTAUT2 with perceived value", International Journal of Information Management, vol. 45(1), 2019, pp. 44-55.

[35] V. Venkatesh, J. Thong, and X. Xu, "Consumer acceptance and user of information technology: Extending the unified theory of acceptance and use of technology", MIS Quarterly, vol. 36(1), 2012, pp. 157-178.

[36] Z. Khlaif, “Teachers' perceptions of factors affecting their adoption and acceptance of mobile technology in K-12 settings", Computers in the Schools, vol. 35(1), 2018, pp. 49-67.

[37] B. W. O'Bannon, S. Waters, J. Lubke, J. Cady, and K. Rearden, "Teachers and students poised to use mobile phones in the classroom", Computers in the Schools, vol. 34(3), 2017, pp. 125-141.

[38] International Society for Technology in Education, National Educational Technology Standards for Administrations, 2009, ISTE.

[39] F. Hussin, J. Ali, and M.S. Z. Noor, Kaedah penyelidikan \& analisis data SPSS, UUM Sintok, Kedah: UUM Press, 2014.

[40] J.W. Creswell, Research design :qualitative, quantitative, and mixed methods approaches (4th ed.), Thousand Oaks, California: SAGE Publications, Inc., 2014.

[41] J. J. F. Hair, W. C. Black, B. J. Babin, and R. E. Anderson, Multivariate data analysis (7th ed.), Essex: Pearson Education Limited, 2014.

[42] G. Darusalam, and S. Hussin. (2018). Metodologi penyelidikan dalam pendidikan: Amalan dan analisis kajian (2nd ed.), Kuala Lumpur: Penerbitan Universiti Malaya, 2018.

[43] M. M. Mokhtar, and M. Jamil, "Mobile technology usage: The shift of focus to cultivate high level thinking skills (HOTS) in the Malay Language Education", Universal Journal of Educational Research, vol. 8(1A), 2020, pp. 156-163.

[44] M. N. Omar, S. N. Ismail, and A. L. Kasim, "The influence of mobile technology adoption among secondary school 
teachers using the UTAUT2 model", International Journal of Recent Technology and Engineering, vol. 8(4), 2019, pp. $3827-3831$

[45] J. Tilton, and M. Hartnett, "What are the influences on teacher mobile technology self-efficacy in secondary school classrooms?", Journal of Open, Flexible and Distance Learning, vol. 20(2), 2016, pp. 79-93.

[46] M. L. Hung, "Teacher readiness for online learning: Scale development and teacher perceptions", Computers \& Education, vol. 94, 2016, pp. 120-133.

[47] M. H. Baturay, S. Gokcearslan, F. Ke, "The relationship among pre-service teachers computer competence, attitude towards computer-assisted education, and intention of technology acceptance", International Journal of Technology Enhanced Learning, vol. 9(1), 2017, pp. 1-13.

[48] A. M. Alzahrani, "Factors that influence secondary school teachers' acceptance of e-learning technologies in teaching in the Kingdom of Saudi Arabia", Journal of Research in Curriculum, Instruction and Educational Technology, vol. 5(2), 2019, pp. 175-196.

[49] O. E. Hatlevik, "Examining the relationship between teachers' self-efficacy, their digital competence, strategies to evaluate information, and use of ICT at school", Scandinavian Journal of Educational Research, 61(5), 2016, pp. 555-567.

[50] L. Shengnan, and P. Hallinger, "Unpacking the effects of culture on school leadership and teacher learning in China", Educational Management Administration \& Leadership, vol. $O(0), 2020$, pp. 1-20.

[51] A. Y. Wong, and K. Daud, "Technology leadership in Malaysia's High Performance School", Journal of Education and E-Learning Research, vol. 4(1), 2017, pp. 8-14.

[52] K. Hesbol, "Design-based school improvement: A practical guide for educational leaders", Impacting Education: Journal on Transforming Professional Practice, vol. 2(1), 2017, pp. 53-55.

[53] P. Govindasamy, M. M. Yunus, and H. Hashim, "Mobile assisted vocabulary learning: Examining the effects on students' vocabulary enhancement", Universal Journal of Educational Research, vol. 7(12A), 2019, pp. 85-92. 